\title{
NOTAS SOBRE O AMOR EM MARIA GABRIELA LLANSOL E EM MARCIA MILHAZES
}

Luiza Rosa (Grupo de Pesquisa Comunicação e Cultura - Barroco e Mestiçagem, PUC-SP; Centro em Movimento)

Recebido a 18/2/2019. Aceite a 15/4/2019.

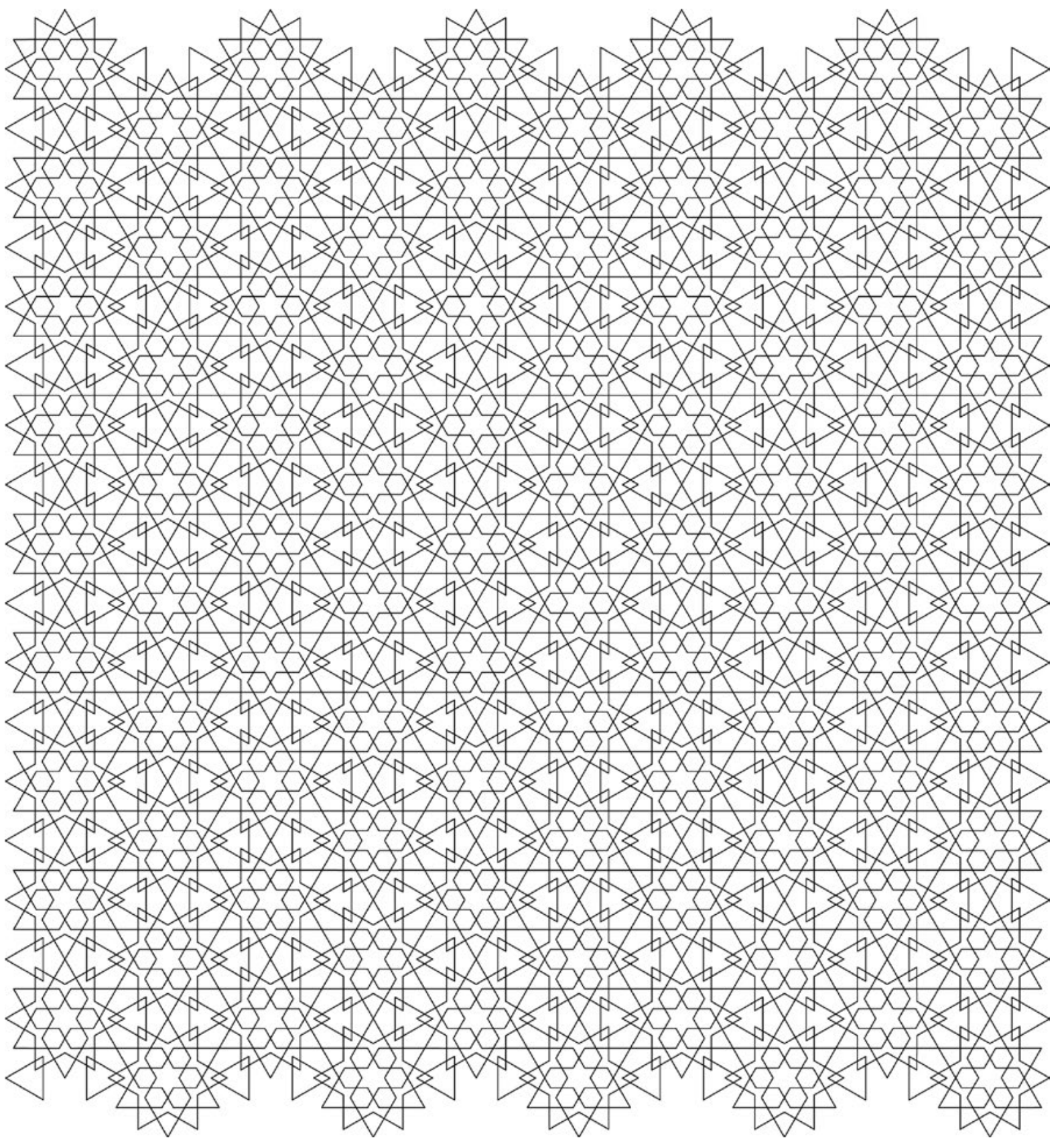


Marulhar também eu era, mas não só de água.

Maria Gabriela Llansol (1987: 176)

Escrevo essas linhas movida pelo desejo de vincular duas superfícies que se encostaram em Lisboa, Portugal, no primeiro semestre de 2016. À época, cursava doutoradol em Comunicação e Semiótica, na Pontifícia Universidade Católica de São Paulo, programa de pós-graduação por meio do qual começava a me aproximar da complexa teia de relações que constituem as coreografias dos espetáculos coreografados pela brasileira Marcia Milhazes, artista da dança contemporânea, que dirige companhia com sede no Rio de Janeiro. Seus espetáculos são solares2, não apenas porque a iluminação compõe com cores amareladas, que remetem ao sol, a ambientes externos, mas também porque os movimentos dos bailarinos conjugados com os da iluminação e com as trajetórias percorridas por eles no espaço desenham formas arredondadas, espiraladas, irregulares, em movimento contínuo.

O que mais me cativou em relação às criações de Milhazes foi o assombro que me provocavam. Traduziam aspectos recônditos de meu universo íntimo, que só se fazia visível em mudez, em silêncio barulhento, em palavras desconexas. Para além disso, me atraiu o fato de seus trabalhos serem lúdicos sem recaírem no infantil.

Foi assombro também o que me deslocou a atenção quando ouvi pela primeira vez frases escritas pela portuguesa Maria Gabriela Llansol. O seu livro O começo de um livro é precioso (2003) estava sendo lido por uma pesquisadora do movimento Susanita, durante uma oficina de escrita performática, ministrada por Margarida Agostinho, enquanto outros quase quinze estudantes de artes escreviam em cadernos, folhas soltas, apoiados no chão, nas costas e ombros dos colegas, aquilo que lhe vinha à mente, naquele momento. Era o início da primavera, estava em meu segundo mês de estágio artístico no Centro em Movimento, plataforma de investigação artística, sediada em Lisboa, liderada pela referida Margarida Agostinho, juntamente com Sofia Neuparth e Cristina Vilhena.

Desta vez o assombro não foi ruidoso, mas silencioso, no entanto, deslocou minha atenção para o agora, pela via da intimidade.

A vinculação entre o assombro provocado pelas obras de Marcia Milhazes, e o assombro provocado pela escrita de Maria Gabriela Llansol, dá forma a um enigma que não tem que ver apenas com acaso de terem sido vivenciados por mim, em dado momento da minha vida. Com efeito, considero que este assombro, tão inerente à dimensão do íntimo nas duas autoras, e pelo qual se manifesta ainda o

1 Cf. Luiza Rosa, Redemunhos do amor: a comunicação barroca em Marcia Milhazes, Tese de Doutorado, PUC-SP, 2018.

2 Ao longo de 25 anos de trajetória, a companhia estreou treze espetáculos para caixa cênica, sendo três trilogias, a primeira atrelada à literatura de Machado de Assis, a segunda às valsas brasileiras e a terceira à música barroca de câmara. Marcia Milhazes também dirigiu e coreografou uma ópera, Pigmaleão, que estreou em 2012 e foi uma leitura da ópera francesa barroca composta por Jean-Philipe Rameau em 1745. 
referido caráter enigmático das duas obras, é provocado em ambas por aquilo que podemos nomear de espelhamento entre a paisagem íntima e a paisagem ao redor, sendo o espelhamento ruidoso, contíguo com paisagens solares cariocas - Brasil - em Milhazes, e o espelhamento silencioso em contiguidade com paisagens belgas, em Llansol.

Sem pretenção de desenvolver aqui uma análise comparativa entre as duas autoras, quero apenas sugerir a maneira como este espelhamento se dá, a meu ver, em ambas, nomeadamente no romance-diário Finita da escritora portuguesa Llansol, em que ecoa a mística do amor de Ibn 'Arabī, e no espetáculo de dança Guarde-me, de Marcia Milhazes, no qual a diretora brasileira diz escrever cartas de amor.

\section{O AMOR EM LLANSOL, PELO AMOR EM IBN ‘ARABĪ: UM ESPELHAMENTO}

Na obra intitulada Ibn Al'Arabi's Barzakh, Salman H. Bashier escreve:

The perfect human being brings together the form of the Real and the form of the cosmos. He is a barzakh between the Real and the cosmos, a raised-up mirror. The Real sees His form in the mirror of the human being, and creation also sees its form in him. He who gains this level has gained a level of perfection more perfect than which nothing is found in possibility.

(BASHIER, 1964: 116-117)

Ele sustenta essa afirmação enquanto fala a respeito de uma tradição profética bastante conhecida entre os muçulmanos em que Allah declara ser um tesouro escondido que quis ser conhecido. Criou as criaturas e se fez conhecido para eles, por meio deles.3

O processo de passagem do não-manifesto para o manifesto, do amor Real e infinito, para o amor terreno, humano, limitado, ocorre por uma relação na qual amante une amor e amado, Deus com a capacidade humana de orar para fazer manifestar em si o divino. Um espelhamento e uma codependência, tanto Deus necessitando do humano para se fazer visto entre os homens, como o humano dependente de Deus, para manifestar em si o amor divino. Considero, pois, que para Ibn 'Arabī o homem perfeito seria aquele que consegue espelhar o amor divino e suportar em si a intersecção entre a natureza divina e a natureza humana.

Esse intermédio, essa intersecção, que recebe o nome de barzah ou istmo aparece no Alcorão (XXV, 53), entre outras passagens, na seguinte: «E foi Ele Quem fez os dois mares, um de água doce e fresca, 
e outro de água salgada e amarga; e fez, entre os dois, um istmo [barzah] e uma barreira intransponível.» (apud BURCKHARDT, 2009, p. 76).

Titus Burkhardt diz mais a respeito de barzah:

[...] a dupla natureza de barzah se reflete em um plano cósmico qualquer pela alternância entre duas fases: da concentração e da expansão. No campo das emoções, tais fases se traduzem mais diretamente nos modos primordiais segundo os quais o psiquismo reage ante ao que considera realidade, quer dizer, por uma parte o temor, que é uma contração sentido ao centro da consciência, e, por outra parte, a alegria ou esperança, que é uma expansão. [...] Quando o temor (al-jawef) e a esperança (ar-rayâ) forem orientados para Allah, Essência universal, não serão, por isso, apagados do campo psíquico, mas ritmizados, por não estar mais submetidos às impulsões desordenadas; poderia-se dizer que serão determinados, de certo modo, pelo "Presente" no tempo e pelo "Centro" no espaço, havendo se convertido em uma só e mesma realidade o polo que os rege e o fim para o qual se inclinam.

(BURCKHARDT, 2009, pp. 81-82; tradução minha)

Estes e outros temas de Ibn 'Arabī, e do Sufismo, foram da maior importância para as reflexões de Maria Gabriela Llansol. A ecscritora portuguesa, no romance-diário Finita, publicado em 1977, em Lisboa, sobreimprime ${ }^{4}$ a concepção de amor de Ibn 'Arabī em suas próprias reflexões, um caminho para desenvolver sua concepção de amor. Na citação a seguir, as nomenclaturas amor, amado e amante, outra maneira de tratar da relação entre homem e Deus pela via da intimidade e da intersecção por um istmo, o barzah, são utilizadas pela autora com desdobramento peculiar:

Jodoigne, 1 de Maio de 1977.

4 Sobreimpressão é um termo cunhado por Llansol para denominar como é que ela dialoga com pensadores que acabam fazendo parte de seu crochê literário, seus romances. A respeito disso, o crítico literário João Barrento diz: «O que dá à visão histórica em Llansol marcas absolutamente diferentes, quer do romance histórico, quer da reflexão filosófica, é o facto de esta dupla perspectiva convergir numa conjectura única que visa recuperar a proximidade do ser através de uma prática libidinal da escrita (e da leitura, da cópia, também práctica da vida) que se desenrola no exterior da história e no interior do Lugar por excelência deste texto, a Casa, que é também o lugar da maior proximidade, lugar da alegria terrena e do regresso, com uma escala mais humanizada que permite reconstituir uma visão-outra da história. No centro da Casa, está também a vontade de proximidade da origem (que a história dos vencedores deixa para trás e ignora, e que aqui, como na leitura de Hölderlin por Heidegger, é da "ordem do segredo"), e no seu interior tudo acontece por inscrição indicial, pequenos desvios, em suma, sobreimpressões.» (BARRENTO, 2011, p. 29). 
Uma toalha,

um véu

são as palavras do dia. Como acordam os sentidos? Os meus, por meias palavras.

$[\ldots]$

Converso com o Augusto $^{5}$ sobre o Amante e parece-nos que o Amante não pode ser uma pessoa, ou seja, máscara que a si mesma se assume como agente vivo ou personagem de um destino próprio. O Amante não pode ser alguém. Se o fosse, procurá-lo colocaria quem o procura na dependência das relações simbólicas que regulam o jogo do amor e do amado.

O Augusto diz-me que o Amante jamais alguém o terá. E eu concordo que o seu acontecimento é imprevisível, assim como a sua evanescência de que me fala Ibn’ Arabi. Não porque queira que se corra atrás dele sem fim, como se lê no Cântico dos Cânticos, mas porque muda de forma.

Não sendo, contudo, uma forma.

O intento do seu movimento é levar o amado a dispensar a forma do amor e da beleza.

Palavras cruéis que só a vontade pode ouvir, como vigia do extremo limite, quando até o próprio Nome é enigma. Quando aí alcança, costuma o amado procurar a Face que, seguindo o seu gosto, melhor se aproxima da Face ideal por que aspira. Mas, mesmo essa, será sempre e só uma Face, cuja majestade e força serão fatalmente inferiores ao impulso que levou o Amado a procurá-la.

Amar é deceptivo.

Vê-se assim que o Nome Enigmático tem um movimento específico: expulsar a Face, na progressiva audição do enigma. Ouvir o Nome, sem o ligar a uma Face, a um sexo, a uma forma particular. Aceitá-lo como simples som, timbre e cadência que dispensa, na sua progressiva enunciação, a forma vocálica e musical.

Mas o que é então o Amante?, pergunto. O teu sexo caminhante para além da repulsa.

(LLANSOL, 1987: 174-175; grifo meu)

5 Augusto Joaquim foi marido da escritora e, durante anos, o principal leitor e crítico de seus textos. 
O espelhamento, propriamente, aparece em outro trecho do mesmo livro: Encontrava-me só.

E só então o marulhar da água ali correndo se fez ouvir como movimento distinto. Criou-se uma progressiva tensão entre mim e a água e soube que me encontrava com o Amante. Marulhar também eu era, mas não só de água. Notei bem que se tratava de um infinito verbal e sonoro que não abolia, não animava, nem sublimava a forma aquática do movimento.

Forma nua em consonância intensa com outra forma nua,

dava realidade ao espaço do Amante. Para além do medo, eu aceitava que nas margens do meu mundo habitual, outros reais criados viessem manifestar-se.

(LLANSOL, 1987: 176-177; grifo meu)

Como se vê, nesta passagem o espelhamento em Llansol, diferente de em Ibn 'Arabī, ocorre não entre Deus e homem, mas entre uma pessoa, ela própria, e a paisagem ao redor, numa íntima dimensão de contiguidade. Ela se percebe em continuum com o marulhar da água do rio.

Continuum é também o que fundamenta os espelhamentos entre ente e paisagem nas composições de Marcia Milhazes.

\section{O AMOR EM MARGIA MILHAZES}

Um dos pilares das composições de Marcia Milhazes, em geral, e de Guarde-me, em particular, é a geração de um movimento contínuo, um continuum infinito. Guarde-me é um espetáculo para caixa cênica, com 50 minutos de duração. Estreou em 2017, em São Paulo. É o segundo espetáculo da terceira trilogia da companhia, criada por meio de pesquisa artística em torno de cartas de anônimos e de artistas reconhecidos, do século XIX e início do século XX, e da escuta de músicas barrocas europeias, essas situadas no século XVIII. A coreografia, direção artística e concepção do espetáculo são de Marcia Milhazes; o elenco é formado por Ana Amélia Vianna e Domênico Salvatore; o desenho de luz foi feito por Glauce Milhazes e Marcia Milhazes; a confecção do figurino é de Eunice Muniz; o conjunto de câmara é composto por Eduardo Antonello (cravo e regência), Roger Lagr (violino barroco e vielle de roda), Pedro Hausselmann (viola da gamba, flautas e gaita de fole). 


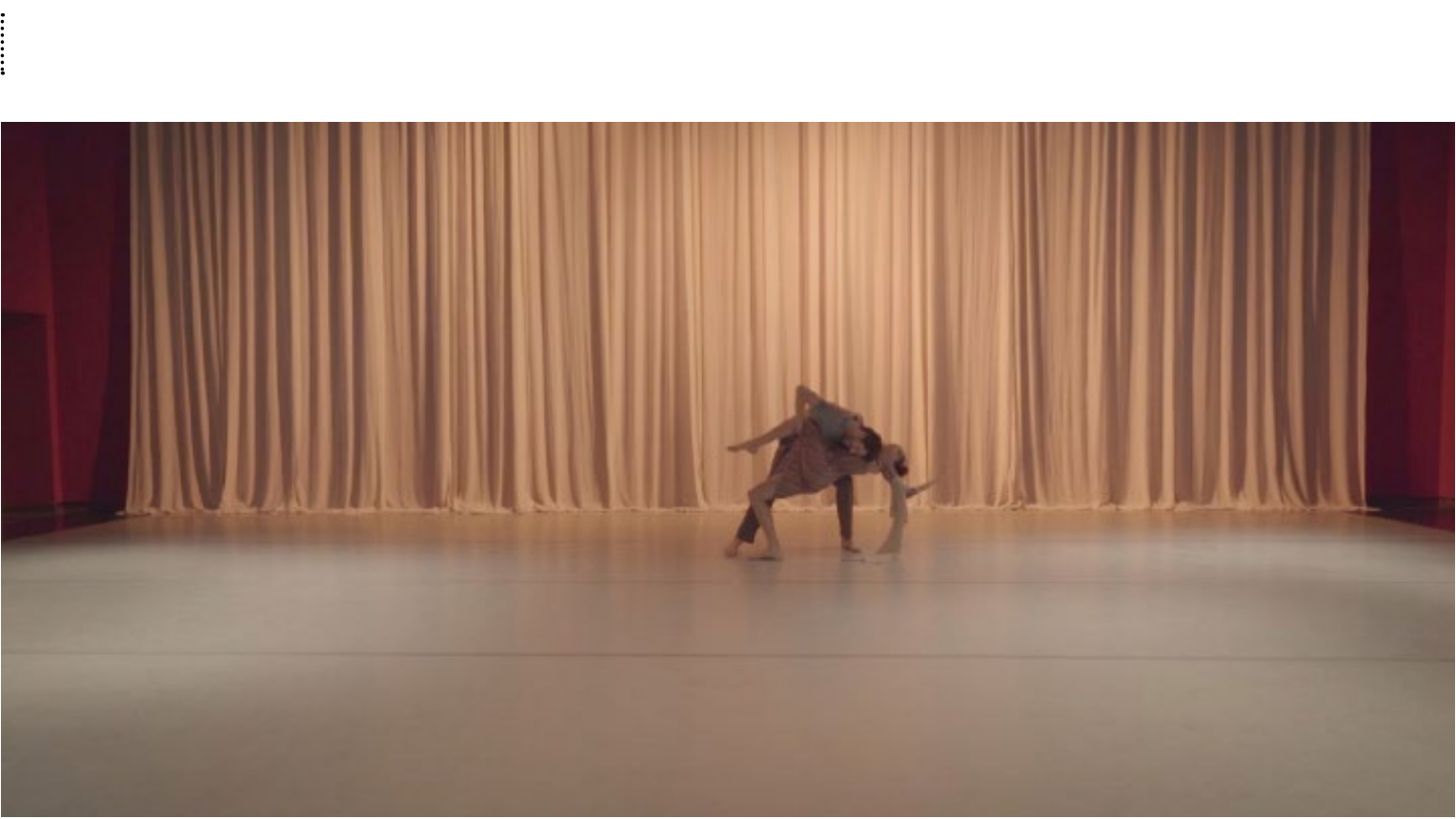

Fig. 1. Trecho de cena inicial de Guarde-me.

Ao longo do espetáculo, são formadas aproximações e distanciamentos constantes, que geram movimento constante, que preenche toda a obra. Como é comum em espetáculos de dança, os bailarinos não saem de cena, estão constantemente envolvidos e implicados com/na composição coreográfica que não é organizada por linhas ou formas ortogonais, mas de acordo com relações que vão sendo estabelecidas entre os bailarinos, que vão ganhando volume e gerando desenhos no espaço. Esse continuum também é formado por movimentos espiralares. Proliferam gestos caboclos ${ }^{6}$, mulatos, mestiços, mesclados com ibéricos, lúdicos, animais, vegetais, que remetem a um tempo outro que não o das ações e reações, mas de recordações, e que comunicam uma intimidade em curso entre os bailarinos e consigo mesmos. Em Marcia Milhazes o amor é uma fonte de água que não cessa de jorrar, cujo gosto coaduna elementos da flora e fauna que convivem ao redor. Este amor-fonte faz da linguagem da autora uma estética que designo da abundância.

6 O termo caboclo designa o mestiço de branco com índio, indivíduo de cor acobreada e cabelos lisos. Sua etimologia descende do tupi kariuoka (kara'iua «homem branco» + oka «casa») (CUNHA, 2010, p. 131). Na gestualidade, a caboclização aparece em agachamentos, acocoramentos, em passar as mãos pelo chão recolhendo ou espalhando. 


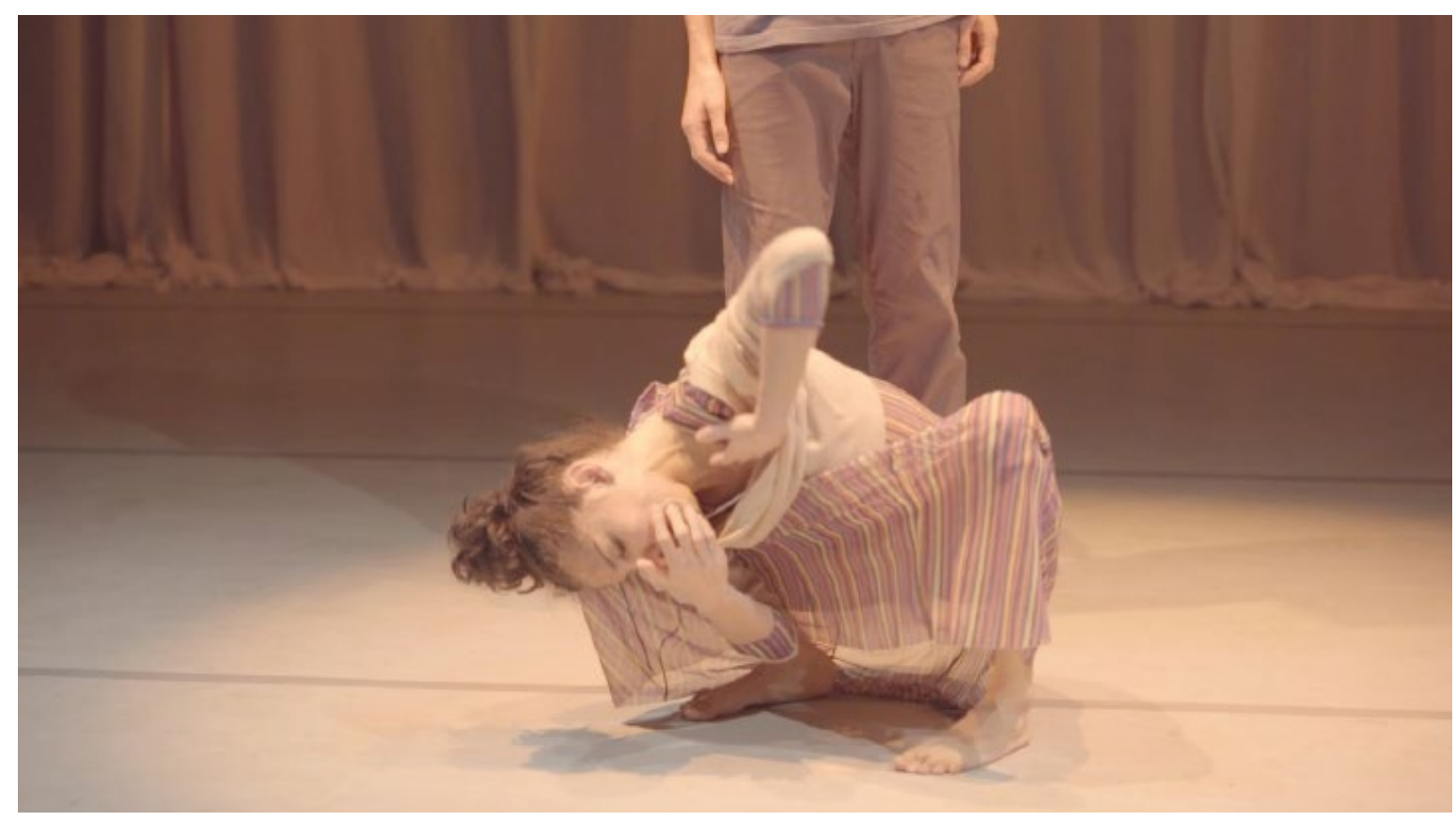

Fig. 2. Gesto caboclo.

Mestiço, nas composições de Milhazes não remete apenas à raça ou cor de pele - apesar do fato de o primeiro bailarino contratado da companhia ser mulato e não ter experiência com balé, ter sido um perfil que agradou à diretora -, mas remete a, como bem explica o pesquisador da cultura latino-americana e tradutor, Amálio Pinheiro:

[...] modos de estruturação barroco-mestiços que acarretam, pela confluência de materiais em mosaico, bordado e labirinto, outros métodos e modos de organização do pensamento. Tais modos não binários desconhecem o dilema entre identidade e oposição: a mestiçagem se constitui como uma trama relacional, conectiva, cujos componentes não remontam saudosa e solitariamente a instâncias aurorais perdidas, mas sim festejam o gozo sintático dessa tensão relacional que se mantém como ligação móvel em suspensão.

(PINHEIRO, 2013, p. 94)

O espelhamento, em Milhazes, ocorre quando o muito, dos gestos, das irregularidades, das paródias, se tornam um único fluxo. O múltiplo coaduna se transformando em um. Esse contraste se assemelha à imagem de um silêncio ruidoso, evocado pela diretora em sinopse de Guarde-me, cheia de contrastes: 
Um novo registro coreográfico inspirado a partir de cartas de amor, que mergulha no campo emocional de um casal. Juntos, sem linha divisória, os dois propõem que o mundo real se confunda com o dos sentidos e travam tentativas de ligações afetivas. Um espaço livre que os move entre a força de um silêncio barulhento e o mundo que os acolhe. Neste espetáculo, Marcia Milhazes retoma o tema sobre paisagens solitárias, no qual o realismo de suas histórias capta a essência interior de cada um, numa tentativa de observar que alguém tão próximo possa estar tão longe.

(MILHAZES, apud ROSA, 2018, p. 62; grifo meu) ${ }^{7}$

Marcia considera que as relações entre os bailarinos é «como se fosse uma conversa, que os prepara para um lugar de infinito». Em entrevista realizada em setembro de 2018, com a diretora, para a escrita de tese de doutorado, Marcia Milhazes disse o seguinte a respeito da performance de Domênico Salvatore, um de seus bailarinos, durante uma cena de Guarde-me:

[...] ele pensa que ele é só o transporte pra não necessariamente estar sendo visível o gesto inscrito. É uma cordilheira de visíveis gestualidades de invisiveis gestos que buscam o sentido, a dramaturgia do que esse homem deseja falar e, se possível, ele não é necessariamente visto pelo público.

(MILHAZES, apud ROSA, 2018, p. 62)

O movimento ininterrupto sobre o qual as composições de Marcia Milhazes está fundamentada, pode ser lido pela perspectiva do que o ensaísta cubano, que se radicou na França, Severo Sarduy, denomina de horror vacui, horror ao vazio presente em toda obra barroca. Por isso, pode-se dizer que a poética de Marcia Milhazes se inscreve no barroco latino-americano. Na literatura, por exemplo, o horror vacui:

[...] renuncia ao seu nível denotativo, ao seu enunciador linear; desaparece o centro único do trajeto dos astros, que até então se supunha circular, para fazer-se duplo quando Kepler propõe como figura desse deslocamento a elipse; Harvey postula o movimento da circulação sanguínea e finalmente o próprio Deus já não será uma evidência central, única, exterior, mas infinidade de certezas de cogito pessoal, dispersão, pulverização que anucia o mundo galáctico das mônadas.

(SARDUY, 1979: 58-59)

7 Entrevista concedida por Marcia Milhazes a Luiza Rosa, no Rio de Janeiro. 
Se o diálogo de Llansol advém do encontro com a obra do místico sufi Ibn 'Arabī, o de Milhazes estabelece-se com o escritor mulato carioca Joaquim Maria Machado de Assis, com compositores brasileiros que assimilam ao erudito formas do popular como Heitor Villa-Lobos, Zequinha de Abreu, Ernesto Nazareth, mas cria, principalmente, de acordo com gestualidade que vai "brotando" nela. A composição se dá de modo radial e inclusivo, montando circuitos. Os elementos vão sendo conjugados na medida em que derivam de núcleos, que vão gerando outros núcleos.

Gestos, ações, cadeias de gestos, circuitos de ações, situações que vão sendo trabalhadas por meio de texturas específicas - oscilações no que tange à espacialidade do movimento, ao peso, ao fluxo, ao tempo, que irão caracterizar aquele momento -, cenas que pedem ambientes de luz apropriados para acolhê-las, que combinam com músicas, que funcionam como «quartos, salas» ${ }^{8}$, nas palavras de Marcia, que, combinadas com o movimento - não por métrica, mas por contiguidade -, vão gerando espaço, pedindo trajetórias irregulares, em vaivém, em ziguezague, arredondadamente; que vão pedindo um figurino para um e outro bailarino, porque conversam com as personas que eles vão compondo na medida de todas essas relações.

Não há, em suas composições: verticalidade; pausa; repetições; ângulos retos (arestas); frontalidade; nem simetria, mesmo assim, há muita precisão.

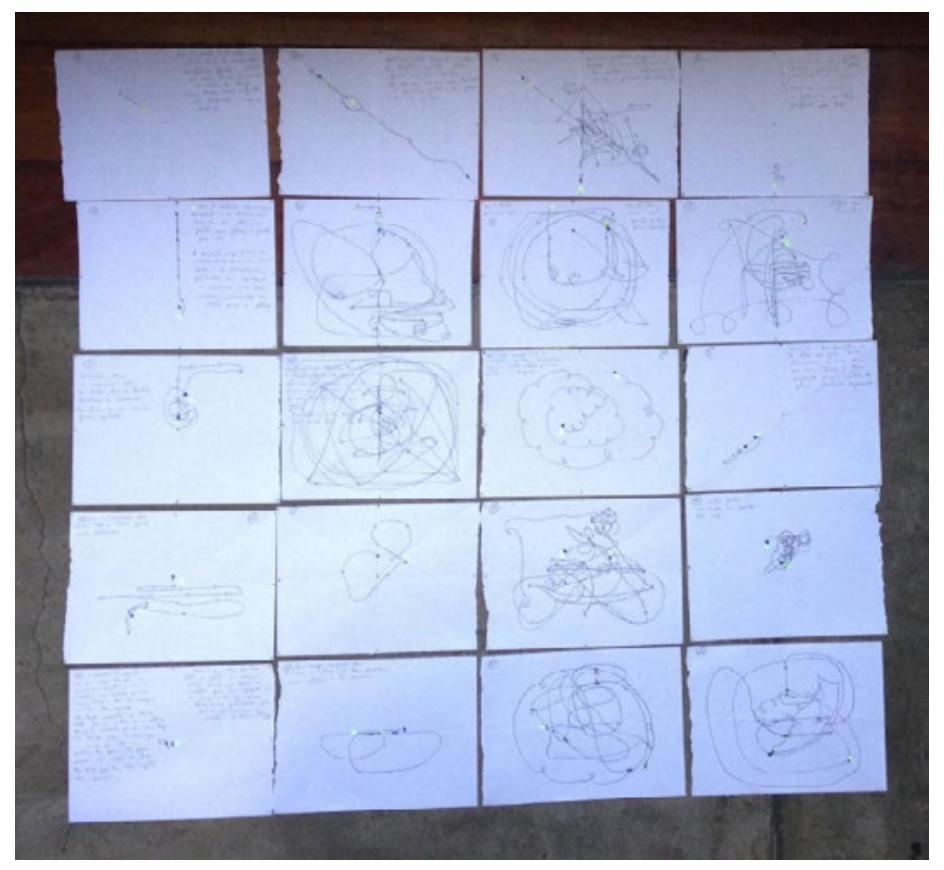

Fig. 3. Desenhos que demonstram trajetórias percorridas pelos bailarinos ao longo do espetáculo.

8 Cito aqui palavras da entrevista mencionada na nota de rodapé anterior, que integram uma passagem ainda inédita da entrevista. 


\section{PALAVRAS FINAIS}

Nestas notas, que advêm de um núcleo experiencial e autobiográfico, parti do pressuposto de haver uma correspondência entre o assombro provocado pelas criações de Llansol e Milhazes, e o artifício ou a experiência do espelhamento. Este inscreve-se, em ambas, por via da íntima, e ao mesmo tempo vasta, dimensão do amor, num enigmático e profundo refletir-se de paisagens interiores e exteriores.

No caso de Marcia Milhazes, o espelhamento ocorre quando os muitos gestos, irregularidades e paródias são coadunados em um único fluxo ininterrupto de movimento, formando um continuum infinito que preenche todo espaço vazio.

Em Llansol, o espelhamento ocorre na forma com que a autora materializa caminhos de sua subjetividade, que mantém íntima relação com o seu entorno, quarto, sala, os cômodos e objetos da casa, bem como na cena que foi destacada, ao longo desta escrita, uma passagem do romance-diário Finita, na qual ela se vincula ao marulhar da água de um rio, sendo contíguo a ele, em continuum infinito.

Não querendo esgotar o enigma que as duas autoras nos apresentam:

Meu mundo interior desaguou pela superficie do agora. Um verdadeiro encontro de rios. Não sei bem por que acordei submersa, o olhar desfocando, compreensão equivocada do meu peso no mundo, mais contido. Ontem, a constatação de que há terra firme por detrás do solo de montanha, que tendo a confundir como minha pele e que aliena a escuta ao esforço.

Me abandono à terra firme. Que paradoxo... O sossego sucede à tormenta.

(Luiza Rosa, São Paulo, abril de 2017) 


\section{REFERÊNGIAS BIBLIOGRÁFIGAS}

BARRENTO, João (2011) (ed.). Europa em sobreimpressão: Llansol e as dobras da história, Lisboa, Assírio e Alvim.

BASHIER, Salman H. (1964), Ibn al'Arabi's barzakh: the concept of the limit and the relationship between God and the World, New York, University of New York.

BURGKHARDT, Titus (2009), Símbolos, Palma de Mallorca, Jose Olañeta.

CORBIN, Henry (1958), L'Imagination Créatrice dans le Soufisme d'Ibn' Arabî, 2e édition, Paris, Flammarion.

LLANSOL, Maria Gabriela (2003), O começo de um lioro é precioso, Lisboa, Assírio e Alvim. (1987), Finita, Lisboa, Rolim.

PINHEIRO, José Amálio (2013). América Latina: barroco, cidade, jornal, São Paulo, Intermeios.

ROSA, Luiza (2018), Redemunhos do amor: a comunicação barroca em Marcia Milhazes, Tese de Doutorado, PUC-SP.

SARDUY, Severo (1979), «O barroco e o neobarroco» in César Fernández Moreno (org.), América Latina em sua Literatura, São Paulo, Perspectiva, pp. 167-184. 